\title{
Quasilinear Utility and Two Market Monopoly
}

\author{
Stephen K. Layson ${ }^{1}$ \\ ${ }^{1}$ Bryan School of Business and Economics, UNCG, Greensboro, NC, USA \\ Correspondence: Stephen K. Layson, Department of Economics, Bryan School of Business and Economics, \\ Bryan 462, PO Box 26170, Greensboro, NC, 27402-6170, USA. E-mail: sklayson@uncg.edu
}

Received: December 23, 2016

Accepted: February 7, 2017

Online Published: February 15, 2017

doi:10.5539/ibr.v10n3p164

URL: https://doi.org/10.5539/ibr.v10n3p164

\begin{abstract}
The use of quasilinear utility functions in economic analyses is widespread. This paper presents an overdue clarification on the implications of quasilinear utility for two market monopoly. The paper begins by deriving the demands facing a two market monopoly from a representative consumer with quasilinear utility. Expressions are derived for the profit margins expressed solely in terms of the own and cross-price elasticities of demand. The paper also analyzes the implications of quasilinear utility for other issues in two market monopoly: pricing below marginal cost in a market, third-degree price discrimination when the monopoly products are substitutes and pricing in the inelastic region of demands.
\end{abstract}

Keywords: quasilinear utility, two product monopoly, third-degree price discrimination

\section{Introduction}

Thanks in large part to Varian $(1985,1992)$ the assumption of quasilinear utility is ubiquitous in economic policy analyses because it allows one to simply measure social welfare as profit plus consumer surplus. This paper presents an overdue clarification of the implications of quasilinear utility for the behavior of two market monopoly and in the process corrects some errors in Varian $(1989,1992)$. After deriving the demands facing a two market monopoly from a representative consumer, the paper derives simple expressions for the monopoly profit margins expressed solely in terms of own and cross-price elasticities of demand. The paper also discusses three other implications of quasilinear utility for two market monopoly: (1) the possibility of pricing below marginal cost (2) the theory of third-degree price discrimination when the monopoly products are substitutes and (3) pricing in the inelastic region of demands.

\section{Method}

\subsection{Quasilinear Utility, Monopoly Demands and Elasticities of Demand}

Let the utility function of the representative consumer be given by $u\left(x_{0}, x_{1}, x_{2}\right)=x_{0}+\varphi\left(x_{1}, x_{2}\right)$, where $x_{0}$ is a numeraire good and $x_{1}$ and $x_{2}$ are the two goods produced by the monopolist. ${ }^{1}$ Assume that $\varphi$ is a twice continuously differentiable, strictly concave function where $\varphi_{1} \equiv \frac{\partial \varphi}{\partial x_{1}}>0, \varphi_{2} \equiv \frac{\partial \varphi}{\partial x_{2}}>0, \varphi_{11} \equiv \frac{\partial \varphi_{1}}{\partial x_{1}}<$ $0, \varphi_{22} \equiv \frac{\partial \varphi_{2}}{\partial x_{2}}<0, \varphi_{12} \equiv \frac{\partial \varphi_{2}}{\partial x_{1}}$ and $\varphi_{11} \varphi_{22}>\varphi_{12}^{2}$

Let the price of the numeraire good be 1 . Utility is maximized subject to the constraint: $x_{0}+p_{1} x_{1}+$ $p_{2} x_{2} \leq y$, where $p_{i}$ is the price of good $i$ and $y$ is the consumer's exogenous income plus monopoly profit. Assuming an interior solution to the consumer's utility maximization problem, the consumer's inverse demand functions are: $p_{1}=\varphi_{1}\left(x_{1}, x_{2}\right) \quad$ and $p_{2}=\varphi_{2}\left(x_{1}, x_{2}\right) \quad$. Note that $\frac{\partial p_{1}}{\partial x_{1}}=\varphi_{11}, \frac{\partial p_{2}}{\partial x_{2}}=\varphi_{22}$ and, by Young's theorem, $\frac{\partial p_{2}}{\partial x_{1}}=\frac{\partial p_{1}}{\partial x_{2}}=\varphi_{12}$. Given the inverse demand functions,

\footnotetext{
${ }^{1}$ The analysis can easily be extended to the case where a monopolist sells $\mathrm{n}$ goods. For the case where the monopolist sells $n$ goods let the utility function be $u\left(x_{0}, x_{1}, \cdots x_{n}\right)=x_{0}+\varphi\left(x_{1}, \cdots x_{n}\right)$.
} 
$\varphi_{1}\left(x_{1}, x_{2}\right)$ and $\varphi_{2}\left(x_{1}, x_{2}\right)$, one might ask under what conditions do the demand functions $x_{1}\left(p_{1}, p_{2}\right)$ and $x_{2}\left(p_{1}, p_{2}\right)$ exist and how are the partial derivatives of these demand functions related to the partial derivatives of the inverse demand functions?

Write the inverse demand functions as

(1) $F^{i}\left(p_{i}, x_{1}, x_{2}\right)=p_{i}-\varphi_{i}\left(x_{1}, x_{2}\right)=0, \quad i=1,2$.

Using the implicit function theorem we know that the demand functions $x_{i}=x_{i}\left(p_{1}, p_{2}\right), i=1,2$, exist in a neighborhood around a point that satisfies equation (1) as long as the Jacobian $|J|=\left|\begin{array}{ll}\frac{\partial F^{1}}{\partial x_{1}} & \frac{\partial F^{1}}{\partial x_{2}} \\ \frac{\partial F^{2}}{\partial x_{1}} & \frac{\partial F^{2}}{\partial x_{2}}\end{array}\right|=\varphi_{11} \varphi_{22}-$ $\varphi_{12}^{2} \neq 0$. Because $\varphi\left(x_{1}, x_{2}\right)$ is by assumption strictly concave it follows that the Jacobian is always positive and that the demand functions $x_{i}=x_{i}\left(p_{1}, p_{2}\right)$ do exist at every point satisfying equation (1).

The implicit function rule of differentiation applied to equation (1) yields:

(2) $\frac{\partial x_{1}}{\partial p_{1}}=\frac{\varphi_{22}}{\varphi_{11} \varphi_{22}-\varphi_{12}^{2}}<0$

(3) $\frac{\partial x_{2}}{\partial p_{2}}=\frac{\varphi_{11}}{\varphi_{11} \varphi_{22}-\varphi_{12}^{2}}<0$

and

(4) $\frac{\partial x_{1}}{\partial p_{2}}=\frac{\partial x_{2}}{\partial p_{1}}=\frac{-\varphi_{12}}{\varphi_{11} \varphi_{22}-\varphi_{12}^{2}}$.

The sign of $\varphi_{12}$ determines whether products 1 and 2 are substitutes, complements or independent. Products 1 and 2 are substitutes, that is $\frac{\partial x_{1}}{\partial p_{2}}=\frac{\partial x_{2}}{\partial p_{1}}>0$, if and only if $\varphi_{12}<0 .{ }^{2}$ Products 1 and 2 are complements, that is $\frac{\partial x_{1}}{\partial p_{2}}=\frac{\partial x_{2}}{\partial p_{1}}<0$, if and only if $\varphi_{12}>0$. The intuition for these latter results is that when products 1 and 2 are substitutes (complements) an increase in production of good 1 lowers (raises) the marginal utility of good 2 and lowers (raises) the maximum amount the representative consumer is willing to pay for good 2. Finally, if $\varphi_{12}=0, \quad \frac{\partial x_{1}}{\partial p_{2}}=\frac{\partial x_{2}}{\partial p_{1}}=0$, the two demand functions are independent. Only in this special case will it be true that $\frac{\partial x_{i}}{\partial p_{i}}=\frac{1}{\varphi_{i i}}=\frac{1}{\frac{\partial p_{i}}{\partial x_{i}}}{ }^{3}$

From the strict concavity of $\varphi\left(x_{1}, x_{2}\right)$ and equations (2) - (4) it also follows that $\frac{\partial x_{1}}{\partial p_{1}} \frac{\partial x_{2}}{\partial p_{2}}>\left(\frac{\partial x_{1}}{\partial p_{2}}\right)\left(\frac{\partial x_{2}}{\partial p_{1}}\right)$. Letting $e_{i j} \equiv \frac{\partial x_{j}}{\partial p_{i}} \frac{p_{i}}{x_{j}}$ be the elasticity of product $j$ with respect to the price of product $i$, the previous inequality expressed

${ }^{2}$ Varian (1989, p. 619, 1992, p. 249) mistakenly states that $\frac{\partial p_{2}}{\partial x_{1}}>0$ when products 1 and 2 are substitutes. Note also from equation (4) that $\frac{\partial x_{i}}{\partial p_{j}} \neq 1 / \frac{\partial p_{j}}{\partial x_{i}}$ for $i \neq j$.

${ }^{3}$ Varian $\left(1989\right.$, p. 618, 1992, p. 249) incorrectly assumes that $\frac{\partial x_{i}}{\partial p_{i}}=1 / \frac{\partial p_{i}}{\partial x_{i}}$ when the two products are substitutes. 
in elasticity form is

(5) $e_{11} e_{22}-e_{12} e_{21}>0$

\subsection{Profit maximization for a two product firm}

Let the profit function for a two-market monopoly be $\pi\left(p_{1}, p_{2}\right)\left(p_{1}-c_{1}\right) x_{1}+\left(p_{2}-c_{2}\right) x_{2}$, where $c_{1}$ is constant marginal cost in market 1 and $c_{2}$ is constant marginal cost in market 2 . The first order conditions for profit maximization are:

$$
\begin{aligned}
& \text { (6) } \pi_{1}=\frac{\partial \pi}{\partial p_{1}}=x_{1}+\left(p_{1}-c_{1}\right) \frac{\partial x_{1}}{\partial p_{1}}+\left(p_{2}-c_{2}\right) \frac{\partial x_{2}}{\partial p_{1}}=0 \\
& \text { (7) } \pi_{2}=\frac{\partial \pi}{\partial p_{2}}=x_{2}+\left(p_{1}-c_{1}\right) \frac{\partial x_{1}}{\partial p_{2}}+\left(p_{2}-c_{2}\right) \frac{\partial x_{2}}{\partial p_{2}}=0
\end{aligned}
$$

Let the profit margin in market $i$ be $m_{i}=\frac{p_{i}-c_{i}}{p_{i}}$. Using the cross-price symmetry result $\frac{\partial x_{1}}{\partial p_{2}}=\frac{\partial x_{2}}{\partial p_{1}}$, equations (6) and (7) with some algebraic manipulation may be rewritten as:

$$
\begin{aligned}
& \text { (8) } m_{1} e_{11}+m_{2} e_{21}=-1 \\
& \text { (9) } m_{1} e_{12}+m_{2} e_{22}=-1
\end{aligned}
$$

Solving for the profit maximizing values of the profit margins yields:

(10) $m_{1}^{*}=\frac{-e_{22}+e_{21}}{e_{11} e_{22}-e_{12} e_{21}}$

(11) $m_{2}^{*}=\frac{-e_{11}+e_{12}}{e_{11} e_{22}-e_{12} e_{21}}$

It is assumed that the second order sufficient conditions for a maximum are satisfied at the profit margins given by equations (10) and (11). For $e_{12}=e_{21}=0$, equations (10) and (11) simplify to $m_{1}^{*}=-\frac{1}{e_{11}}$ and $m_{2}^{*}=-\frac{1}{e_{22}}$

The profit margin expressions given by equations (10) and (11) above are similar but somewhat simpler than expressions developed by Forbes $(1988,62)$. Forbes' expressions for the profit maximizing profit margins are: $m_{1}^{*}=\frac{-e_{22}+e_{12} \frac{R_{2}}{R_{1}}}{e_{11} e_{22}-e_{12} e_{21}}$ and $m_{2}^{*}=\frac{-e_{11}+e_{21} \frac{R_{1}}{R_{2}}}{e_{11} e_{22}-e_{12} e_{21}}$, where $R_{i}=p_{i} x_{i}$. Assuming cross-price symmetry it is easy to show that $e_{21}=e_{12} \frac{R_{2}}{R_{1}}$ and $e_{12}=e_{21} \frac{R_{1}}{R_{2}}$. Tirole's $(1988,70)$ expressions for the profit maximizing profit margins in the two good case are: $m_{1}^{*}=-\frac{1}{e_{11}}-m_{2}^{*} \frac{R_{2} e_{12}}{R_{1} e_{11}}$ and $m_{2}^{*}=-\frac{1}{e_{22}}-m_{1}^{*} \frac{R_{1} e_{21}}{R_{2} e_{22}}$, which with some algebra can be shown to be equivalent to Forbes' expressions.

\section{Results}

\subsection{Pricing below Marginal Cost under Two Market Monopoly}

It has been well known for some time that if the two products are complements then it's possible that price may be below marginal cost in one market. ${ }^{4}$ See Allen $(1938,359-62)$ and the references cited therein. Without loss

${ }^{4}$ If price were below marginal cost in both markets the monopolist's profit would be negative. 
of generality let $m_{1}^{*}>m_{2}^{*}$. From equation (10) the condition for price to be below marginal cost in market 2 in the present model is $e_{11}-e_{12}>0$. Because $e_{11}$ is assumed to be negative, for the profit margin to be negative in market 2 we must have $e_{12}<0$ and $\left|e_{12}\right|>\left|e_{11}\right|$. For example, a baseball team that sells beer (product 2) and tickets (product 1 ) would price beer below its marginal cost if lowering the price of tickets by $1 \%$ led to a greater \% increase in beer sold than the \% increase in tickets sold.

\subsection{Third-degree Price Discrimination When Demands Are Interdependent}

Suppose a monopolist sells a single product with the equal marginal costs in two markets at different prices but the two markets are not perfectly sealed off from each other so that there is some substitution between the markets. See for example Varian's discussion $(1989,1992)$ of this subject. An example of this type of price discrimination is a movie theatre that shows afternoon movies at a lower price than the same movie shown at night. Because movies shown at night and during the day are substitutes, $e_{12}, e_{21}>0$. Profit maximization for the price discriminating monopolist requires satisfying equations (10) and (11). The condition for $m_{1}^{*}>m_{2}^{*}$ is $-e_{22}+e_{21}>-e_{11}+e_{12}$. Note if $e_{12}=e_{21}$ then the previous condition reduces to $\left|e_{22}\right|>\left|e_{11}\right|$, which is the well known result that a price discriminating monopoly has a lower profit margin in the more elastic market.

\subsection{Pricing in the Inelastic Regions of Demands}

It is well known that an unregulated single-product monopolist will never operate in the price inelastic region of demand because that implies marginal revenue is negative. We now investigate whether this result extends to the case of a two-market monopoly. Because $m_{1}^{*} \leq 1$ and $m_{2}^{*} \leq 1$, we can derive the following inequalities from equations (10) and (11):

(12) $e_{21}\left(e_{12}+1\right) \leq e_{22}\left(e_{11}+1\right)$ (holds with equality if $m_{1}^{*}=1$ )

(13) $e_{12}\left(e_{21}+1\right) \leq e_{11}\left(e_{22}+1\right)$ (holds with equality if $m_{2}^{*}=1$ )

If $\left|e_{11}\right|<1$ then from inequality (12) we must have $e_{12}<0, e_{21}<0$ and $\left|e_{12}\right|<1$. In words, if demand is inelastic in market 1 , then the two products must be complements and the absolute value of $e_{12}$ must be less than 1. Similarly, if demand is price inelastic in market 2 inequality (13) implies that the two products must be complements and that the absolute value of $e_{21}$ must be less than 1 . To verify that both markets can have price inelastic demands, let $e_{11}=-.8, e_{22}=-.9, e_{12}=e_{21}-.5$. From equations (10) and (11) we find $m_{1}^{*}=.851$ and $m_{2}^{*}=.638$.

If marginal cost is zero in a market, the two products are complements and the absolute values of the cross-price elasticities are less than 1 , then it must be the case that demand is inelastic in that market. Consider the case where $c_{1}=0$ and hence $m_{1}^{*}=1$. If $e_{12}, e_{21}<0$, and $\left|e_{12}\right|<1$ then it follows from equation (12) that $\left|e_{11}\right|<1$. Similarly if $c_{2}=0$ and hence $m_{2}^{*}=1$, then $e_{12}, e_{21}<0$, and $\left|e_{21}\right|<1$ implies $\left|e_{22}\right|<1$. Finally, consider the case where $c_{1}=c_{2}=0$ which implies $m_{1}^{*}=m_{2}^{*}=1$, then $e_{12}, e_{21}<0,\left|e_{12}\right|<1$ and $\left|e_{21}\right|<1$ implies $\left|e_{11}\right|<1$ and $\left|e_{22}\right|<1$.

Major league sports teams provide a good application of ticket pricing in the inelastic region of demand. All major league sports teams can be regarded as multiproduct monopolies selling complementary goods: tickets and concessions. The marginal cost of allowing another person to see a game is nearly zero as long as there are empty seats. It follows from the discussion above that ticket prices should be set in the inelastic region of demand as long as the absolute value of the cross-price elasticity of demand for concessions with respect to ticket prices is less than 1. Fort (2004) and Krautmann and Berri (2007) both argue forcefully that ticket pricing in the inelastic region of demand is commonplace in sporting events.

\section{Discussion}

This paper has clarified several implications of the assumption of quasilinear utility for two market monopoly. After deriving the demands facing a two market monopoly from a representative consumer, this paper derives 
expressions for profit maximizing profit margins expressed solely in terms of own and cross-price elasticities of demand. The paper also derives and discusses the condition for a two market monopoly to price one of its products below marginal cost and clarifies the theory of third-degree price discrimination when the two monopoly products are substitutes. The paper ends with a discussion of pricing in the inelastic region of demand under two market monopoly. It is shown that a two market monopolist may (and in some conditions must) operate in the price inelastic region of demand in one or even both markets.

\section{References}

Allen, R. G. D. (1938). Mathematical Analysis for Economists, St. Martin's Press, New York.

Forbes, K. (1988). Pricing of related products by a multiproduct monopolist. Review of Industrial Organization, 3, 55-73. https://doi.org/10.1007/BF02229566

Fort, R. (2004). Inelastic sports pricing. Management and Decision Economics, 25, 87-94. https://doi.org/10.1002/mde.1108

Krautmann, A., \& Berri, D. (2007). Can we find it at the concessions? Journal of Sports Economics, 8, 183-191. https://doi.org/10.1177/1527002505275093

Tirole, J. (1988). The Theory of Industrial Organization, The MIT Press, Cambridge, Massachusetts.

Varian, H. (1978). A note on locally constant income elasticities. Economics Letters, 1, 9-13. https://doi.org/10.1016/0165-1765(78)90087-3

Varian, H. (1985). Price discrimination and social welfare. American Economic Review 75, 870-875.

Varian, H. (1989). Price Discrimination, in: Schmalensee, R., Wilig, R. (Eds.) Handbook of Industrial Organization, I, Elsevier Publishers B. V, 597-654. https://doi.org/10.1016/S1573-448X(89)01013-7

Varian, H. (1992). Microeconomic Analysis, third ed. Norton New York.

Willig, R. (1976). Integrability implications for locally constant demand elasticities. Journal of Economic Theory, 12, 391-401. https://doi.org/10.1016/0022-0531(76)90035-1

\section{Copyrights}

Copyright for this article is retained by the author(s), with first publication rights granted to the journal.

This is an open-access article distributed under the terms and conditions of the Creative Commons Attribution license (http://creativecommons.org/licenses/by/4.0/). 